\title{
Internet: a negatividade do discurso da mídia versus a positividade da experiência pessoal. À qual dar crédito?
}

\author{
Ana Maria Nicolaci-da-Costa \\ Pontificia Universidade Católica do Rio de Janeiro
}

\begin{abstract}
Resumo
Tendo em vista a insistência da mídia brasileira em divulgar resultados de pesquisas estrangeiras, principalmente norte-americanas, que sistematicamente apontam os efeitos negativos do uso intensivo da Internet, foi realizada uma pesquisa em profundidade com usuários "pesados" brasileiros. Foram minuciosamente entrevistados 20 homens e mulheres que se conectam diariamente à Rede durante no mínimo duas horas de seu tempo de lazer. O levantamento de seus hábitos, preferências e opiniões revela que esses usuários enfrentam um dilema de difícil solução. Por um lado, sequer cogitam se contrapor a um discurso que lhes é passado como científico - e, portanto, confiável -, mesmo quando este avalia o uso intensivo da Internet sob a ótica da patologia. Por outro, são instados por seu cotidiano, em cuja rotina a Internet se inseriu sem maiores problemas, a dar crédito à sua própria experiência positiva na Rede. Para resolver o problema, lançam mão de estratégias de distanciamento, relativização e até mesmo desqualificação bem-humorada do discurso da patologia divulgado pela mídia.
\end{abstract}

Palavras-chave: Internet, Efeitos patológicos, Experiência positiva, Mídia, Usuários brasileiros

\begin{abstract}
Internet: Negative media discourse versus positive personal experience. Which should we rely on? Given Brazilian media's insistence in making public the results of foreign, mainly American, investigations that systematically point out the negative effects of the intensive use of the Internet, an in-depth research was conducted on Brazilian "heavy" users. Twenty men and women, who log on to the Net daily for at least two hours of their leisure time, were interviewed in detail. Knowledge of their habits, preferences and opinions reveals that these users are faced with a difficult dilemma. On the one hand, they do not dare criticize the negative discourse that reaches them through the media. They consider it trustworthy because of its alleged scientific bases. On the other hand, they are urged by their daily life, which has absorbed the Internet in its routine without any major problems, to give credit to their own positive experience on the Net. In order to solve the problem, they resort to strategies that distance themselves from what the media say and even disqualify it in a good-humoured manner.

Key words: Internet, Pathological effects, Positive experience, Media, Brazilian Net users
\end{abstract}

A midia norte-americana e as pesquisas sobre o uso intensivo da Internet

É espantosa a velocidade com que se espalhou pelos Estados Unidos, e de lá para o mundo, a crença de que a Internet pode gerar comportamentos patológicos. Tudo começou na esteira da maciça difusão da Internet naquele país, em meados da década de 1990.

Nessa época, alguns psicólogos norte-americanos, entre os quais Kimberly Young $(1996,1998)$ e David Greenfield
(1999, 2000), começaram a divulgar a existência de um novo comportamento compulsivo que, segundo eles, se assemelhava ao do jogo patológico catalogado no Diagnostic and Statistical Manual of Mental Disorders (DSM-IV). Esta nova patologia foi chamada de Internet addiction ou Pathological Internet Use (PIU) e tanto Young quanto Greenfield passaram a se dedicar ao seu tratamento. ${ }^{1}$

Os estudos desses dois psicólogos foram seguidos de muitos outros sobre os efeitos negativos do uso intensivo da Rede. Todos ganharam muito espaço na mídia 
nacional (alguns, inclusive, na primeira página de jornais do porte do Washington Post e do New York Times). Em sua edição de 7 de setembro de 1998, por exemplo, o jornal Washington Post deu ampla cobertura a uma pesquisa levada a cabo por uma equipe de pesquisadores liderada por Robert Kraut, professor da Carnegie Mellon University, cujos resultados indicavam que mesmo as atividades sociais online, como a participação em salas de bate-papo e o uso de e-mail, geram solidão e depressão (ver, também, Kraut et al., 1998).

Outra pesquisa que encontrou muita receptividade na mídia norte-americana foi aquela levada a cabo pelo Stanford Institute for the Quantitative Study of Society (SIQSS, 2000). De acordo com o professor Norman Nie, diretor do SIQSS, o estudo revela que o uso intensivo da Internet está gerando uma legião de pessoas solitárias que não se interessam pelas obrigações e prazeres do mundo real e substituem vínculos afetivos fortes e reais por vínculos afetivos mais fracos e virtuais.

Resumindo os achados de Young, Greenfield, Kraut e Nie chegamos ao seguinte e alarmante quadro: a Internet pode gerar a compulsão, a dependência e os problemas pessoais e sociais característicos do vício. O uso intensivo da Rede, por sua vez, pode ter como conseqüência o isolamento social - e a solidão e depressão dele decorrentes - em virtude da substituição de relacionamentos e atividades reais por relacionamentos e atividades virtuais. É isto o que vem sendo passado pela mídia para o público em geral desde o início da difusão da Internet.

Recentemente, porém, os resultados gerados por essas e outras pesquisas (ver, por exemplo, aquelas mencionadas na seção sobre as repercussões no Brasil) vêm sendo avaliados criticamente, individualmente ou em conjunto, por pesquisadores, acadêmicos em geral, jornalistas, etc. Trabalhos que contestam a validade desses primeiros achados, apontam as inconsistências entre os resultados produzidos por diferentes pesquisas e criticam o papel da mídia em sua divulgação, vêm encontrando espaço principalmente em periódicos especializados.

Em abril de 2000, por exemplo, o Monitor on Psychology, jornal da American Psychological Association, apontava os exageros no debate sobre a Internet addiction dedicando-lhe, entre outros, os artigos críticos intitulados Is Internet addiction real?, de autoria de Tori deAngelis e Linking up online, de Rebecca A. Clay.

Em Linking up online, além de oferecer uma panorâmica dos resultados conflitantes das pesquisas sobre isolamento social, Clay (2000) menciona explicitamente o medo que a mídia norte-americana vem gerando ao dar tanta ênfase aos aspectos negativos da vida online:
A pesquisadora Kathlyn Y. A. McKenna, PhD, e o professor John A. Bargh, PhD, do departamento de psicologia da Universidade de Nova York, comparam as notícias negativas a respeito da Internet ao medo de novas tecnologias que, no passado, incitou as pessoas a resistirem ao telefone na crença de que outros poderiam ouvir suas conversas em casa mesmo com o telefone no gancho. (p. 21, minha tradução)

Já deAngelis (2000) revela a percepção que hoje é possível termos tanto da fragilidade dos primeiros resultados sobre a Internet addiction, quanto do exagero da mídia a respeito dos comportamentos patológicos supostamente gerados pelo uso da Rede:

Se acreditarmos no que lemos, o "vício na Internet" está transformando os EUA numa nação de decadentes. (...) No entanto, apesar da proeminência do assunto, os estudos publicados sobre o vício na Internet são raros. (...) Nesse meio tempo, muitos psicólogos chegam a duvidar que vício seja o termo correto para descrever o que acontece com as pessoas quando elas passam muito tempo online. (p. 24, minha tradução)

Parece-nos que 2000 configurou-se como o ano do amadurecimento proporcionado por uma visão menos precipitada e mais realista da Internet. No Online Journalism Review, publicado online em 25 de abril de 2000, o artigo Internet statistics unsound: media reporting on Internet studies misses fundamental problems - assinado por Cristopher Weare (2000), professor de comunicação na Universidade da Carolina do Sul, - também assume um tom bastante crítico do papel da mídia norte-americana na divulgação dos efeitos negativos da Internet baseados em resultados "inconclusivos e potencialmente enganadores".

(...) Por duas vezes nos dois últimos anos, o New York Times dedicou ampla cobertura de primeira página a dois obscuros trabalhos acadêmicos sobre os impactos sociais e psicológicos do uso da Internet. Os pesquisadores são unânimes em nos dar más notícias. (...) [E, fazendo referência aos estudos de Kraut e Nie discutidos acima, Weare afirma:] Um declara que "mesmo poucas horas por semana passadas online [geram] níveis mais altos de depressão." O outro alerta que "a Internet [está] criando uma nova e generalizada onda de isolamento social.” (...) O problema começa quando a busca de notícias por parte de um repórter se alia ao desejo de reconhecimento público por parte de um membro da academia. (...) Estudos que são fracos, inconclusivos, e potencialmente enganadores são apresentados como sérios e significativos. (consulta online, minha tradução.)

De qualquer modo, algo de positivo já teve início. É chegada a hora de se fazer um balanço crítico dos estágios iniciais da difusão da Internet. Pelo menos, nos EUA! 


\section{As repercussões no Brasil}

Em contraste com o que vem acontecendo nos EUA, a mídia brasileira parece reinar soberana e incontestada.

Desde a implantação dos primeiros provedores comerciais brasileiros, no ano de 1995, as várias pesquisas norteamericanas mencionadas acima e muitas outras - inglesas, canadenses, francesas, suíças, etc. - vêm encontrando ampla divulgação tanto na mídia especializada em Internet (ver, por exemplo, os primeiros volumes das revistas Internet World e Internet.br) quanto nos jornais e revistas de ampla circulação no Brasil. Dou alguns exemplos que, mesmo escolhidos ao acaso, mostram o quadro conflitante e alarmista ao qual os brasileiros - usuários da Rede ou não - tiveram acesso nos últimos anos.

No dia 20 de novembro de 1996, ou seja, nos primeiros tempos da difusão da Internet no Brasil, o jornal Folha de São Paulo divulgava os primeiros estágios do já mencionado trabalho de Kimberly Young, na matéria intitulada Instituições tentam curar viciados em Internet. Segue-se um pequeno trecho ilustrativo:

A nova doença foi identificada em janeiro de 1995, e seu histórico e sintomas podem ser encontrados na homepage mantida pelo Centro para Viciados On line da Universidade de Pittsburgh (http://www.pitt.edu/ ksy/). O Centro, dirigido pela doutora Kimberly S. Young (e-mail: ksy+@pitt.edu), promove workshops com profissionais de saúde, dá consultoria a instituições médicas e educacionais e conduz uma extensa pesquisa na própria rede sobre $\mathrm{o}$ assunto (consulta online).

Não muito tempo depois, em 7 de agosto de 1997, o vício na Internet - desta feita comparado ao vício em cocaína e não mais ao vício em jogo como no caso de Kimberly Young - chegava à primeira página do Jornal do Brasil. Médico diz que Internet vicia como cocaína, é o título da chamada, na qual lê-se:

A Internet vicia. Essa é a conclusão do psicólogo britânico Mark Griffiths, que, após um ano e meio de pesquisas, definiu o perfil do viciado: é o adolescente solitário que usa o computador para criar um universo paralelo. Alguns sintomas podem indicar o grau de dependência semelhante ao da cocaína (p. 1).

Em 8 de dezembro de 1997, um outro grande jornal carioca - O Globo - publicava uma matéria intitulada Viciados em Internet. Desta emergia um perfil de risco bastante diferente daquele dos jovens solitários da matéria do Jornal do Brasil. Desta vez, os usuários em risco de serem vitimados pelo vício eram os executivos:

O número de viciados em informações obtidas na Internet está aumentando em todo o mundo, segundo estudo realizado pela agência Reuters. Um total de $53 \%$ das mil pes- soas entrevistadas admitiu que sofrem de incontrolável ânsia de obter informação pela Internet. O estudo foi realizado com executivos de ambos os sexos na Grã-Bretanha, EUA, Irlanda, Alemanha, Cingapura e Hong Kong (p. 20)

Em 30 de agosto de 1998, a Folha de São Paulo retomava o assunto no artigo Internet vira vício para $10 \%$ dos usuários. Divulgava uma nova pesquisa, agora canadense, e mais um perfil de risco que pouco tinha a ver com os dois primeiros:

[Segundo o psicólogo canadense Jean-Pierre Rouchon], homens entre 25 e 35 anos com um bom nível socioeconômico, que passam incontáveis horas trabalhando na frente dos seus computadores, são o principal grupo de risco para um novo tipo de dependência que começa a ser detectado: o vício em Internet (consulta online).

São inumeráveis os artigos de jornais e revistas brasileiros que discorreram sobre o vício na Internet de 1996 aos dias de hoje. Para finalizar esta série de exemplos, creio ser útil citar um artigo da revista Superinteressante, do mês de outubro de 2000, que se propunha a fornecer ao leitor uma visão panorâmica do assunto. O título da matéria, escrita por Jomar Morais, é Armadilha digital. E no que consiste essa armadilha? Novamente na dependência, no isolamento social, na substituição da realidade "real" pela virtual e em prejuízos para o desempenho profissional.

Estima-se que pelo menos 200.000 americanos perderam o controle sobre o uso da Internet e hoje sofrem de um mal catalogado pela Associação Americana de Psicologia como PIU (Pathological Internet Use) ou Uso Doentio da Internet, cujo sintoma básico é o uso preferencial e, muitas vezes, exclusivo da Internet sobre todas as outras atividades do cotidiano. Suas vítimas se tornam incapazes de controlar o número de horas que permanecem ligadas na rede, numa onda compulsiva que acaba isolando-as de familiares e amigos e comprometendo seu desempenho profissional. (p. 66)

No que diz respeito ao contexto norte-americano, vimos anteriormente que, passados os primeiros estágios da difusão da Internet, alguns acadêmicos e psicólogos começaram a adotar uma atitude mais distanciada, crítica e cautelosa em relação à exposição, feita pela mídia, de resultados tão inconsistentes entre si como os que acabam de ser apresentados. E no contexto brasileiro, o que está acontecendo?

\section{A necessidade de investigar os impactos do discurso da midia sobre os usuários brasileiros}

Ao contrário do que vem ocorrendo nos Estados Unidos, até o momento não há resultados divulgados de pesquisas nacionais sobre o uso intensivo da Internet (ver Leitão e Nicolaci-da-Costa, 2000). Esse uso parece ser abordado quase que exclusivamente pela mídia. Tam- 
bém não parece haver muita preocupação, por parte de acadêmicos e profissionais de saúde mental, com aquilo que é divulgado pela imprensa para o público em geral.

Assim sendo, os milhões de usuários brasileiros da Rede são, como vimos, bombardeados com informações fragmentadas, alarmistas e contraditórias sobre todos os tipos de patologia potencialmente gerados pela Internet, sem que ao menos sejam avaliados os efeitos que essas informações têm sobre eles. É necessário dar início ao preenchimento dessa lacuna. Essa é a nossa intenção.

Este estudo não tem o intuito de avaliar criticamente as várias pesquisas realizadas no exterior. Não pretende tampouco determinar a existência ou não de diferentes tipos de patologia gerados pelo uso da Rede entre os brasileiros. A proposta deste trabalho é a de investigar os impactos que o discurso patologizante da mídia vem tendo sobre os nossos conterrâneos que fazem uso intensivo da Internet, a partir dos resultados de uma pesquisa em profundidade sobre seus hábitos, preferências e opiniões. Pretende, ainda, examinar como esses usuários integram (se é que o fazem) a visão negativa da Rede, divulgada pela imprensa off e online, à sua própria experiência na Internet.

Tendo como base o conhecimento alcançado neste e em outros trabalhos (ver, por exemplo, Nicolaci-da-Costa, 1998, 1999 e 2000), talvez seja possível oferecer, aos brasileiros que se conectam à Internet regularmente, uma reflexão coerente a partir da qual possam avaliar tanto os seus próprios comportamentos quanto os discursos negativos, sensacionalistas e, muitas vezes, conflitantes aos quais são freqüentemente expostos.

\section{A pesquisa}

\section{Metodologia}

Em seu Internet Addiction Guide (1999), o psicólogo norte-americano John M. Grohol aponta que não há consenso em relação à quanto tempo um "viciado" gasta online. Na realidade, os mais conhecidos estudos sobre o vício na Internet (ver Young, 1996, 1998, e Greenfield, 1999, 2000) tendem a enfatizar que o tempo gasto na Rede é menos importante do que os danos pessoais e sociais que ele supostamente causa.

No que diz respeito ao uso "pesado" da Rede, a situação é ainda mais vaga. Poucos são os estudos que timidamente sugerem algum patamar básico para classificar um usuário como "pesado". Este é o caso do SIQSS (2000), que sugere um patamar de 10 horas semanais. É também o caso de um estudo realizado por Alvin Cooper (citado em deAngelis, 2000) que parece considerar "pesado" um uso de no mínimo 11 horas semanais.

Perante esse quadro vago, tornou-se necessário que encontrássemos uma definição operacional do que vem a ser um "usuário pesado". Dado nosso interesse no ponto de vista dos usuários brasileiros da Internet, minha equipe e eu resolvemos entrevistar pessoas que dela faziam uso diário (estas nos foram indicadas por usuários conhecidos) com a intenção de apreender o que elas viam como um "uso pesado" da Rede.

Para isso, fizemos uso das entrevistas-piloto, que normalmente realizamos para testar nossos instrumentos. A partir dos depoimentos coletados nas 13 entrevistas realizadas nessa fase, chegamos à conclusão de que, aos olhos desses entrevistados, um "usuário pesado" é aquele que passa, no mínimo, duas horas diárias conectado à Internet. Como esta definição era semelhante àquelas sugeridas pelos estudos do SIQSS e de Alvin Cooper (e até um pouco mais rígida do que elas), tornouse o principal critério de recrutamento dos sujeitos que participariam da pesquisa.

A este critério acrescentamos outros, quais sejam:. (1) Os participantes deveriam se conectar exclusivamente de casa, por opção, em seu tempo disponível para lazer. Queríamos evitar as situações em que os usuários se conectam por obrigação ou necessidade, como em diversos ambientes de trabalho e estudo; (2) Todos os participantes deveriam já estar usando a Internet por, no mínimo, seis meses. Queríamos investigar se os sujeitos já tinham uma rotina de uso estabelecida; (3) Os participantes deveriam ter, pelo menos, 16 anos de idade. Queríamos que fossem capazes de ter alguma consciência dos impactos do uso da Rede sobre si mesmos; (4) Os participantes deveriam, no mínimo, estar cursando o segundo grau. Queríamos ter a garantia de um patamar de instrução comum a todos. Não foram feitas quaisquer restrições à idade, sexo ou profissão. Estes dados foram, no entanto, coletados.

Com base nesses critérios, foram recrutados vinte sujeitos a partir de indicações de usuários conhecidos dos pesquisadores. Desses, quatorze tinham entre 20 e 27 anos e três tinham entre 16 e 19. Os outros três eram mais velhos: 39, 44 e 56 anos de idade. Devido ao grande número de jovens, muitos dos nossos sujeitos eram estudantes de segundo ou terceiro grau. Havia, também, jornalistas, médicos (sendo que um deles era também psicanalista), professores, consultores de informática e um advogado. Todos eram experientes usuários da Internet.

\section{Coleta de dados}

A coleta de dados foi feita a partir de vinte entrevistas individuais, de cerca de uma hora de duração. Essas entrevistas foram realizadas em locais escolhidos pelos próprios sujeitos de modo a torná-las informais e descontraídas. Isso porque, para nós, é fundamental que os sujeitos não se sintam inibidos e possam se abrir com 
o entrevistador (a esse respeito ver, por exemplo, Labov, 1973 e Nicolaci-da-Costa, 1989).

Para guiá-lo, o entrevistador dispunha de um roteiro construído com esta finalidade (a respeito da construção de roteiros, ver Nicolaci-da-Costa, 1989). O roteiro era composto de 25 perguntas principais, que poderiam ser desmembradas em outras, para maior aprofundamento. Todas as perguntas eram abertas e versavam sobre:

- Hábitos do usuário: quando liga o computador; quais os programas que usa na Rede; quando e quantas vezes por dia checa e-mail; quantos e-mails tem (por quê); quantos programas usa ao mesmo tempo (por quê); quanto tempo por dia gasta na Rede (fazendo o quê); qual o máximo de horas que ficou conectado (fazendo o quê); o que gosta de usar na Internet.

- Sentimentos, emoções e opiniões (próprias ou dos outros sobre si): o que acha da Rede e do uso que faz dela; o que os outros acham do uso que faz da Rede; o que sente quando se conecta (por quê); o que sente quando não consegue conexão (por quê); o que sente quando não tem acesso ao computador (por quê), o que sente quando se desconecta (por quê); se já teve, na Rede, alguma emoção/ sensação inédita (em caso positivo, descrever); se acha que a Internet pode gerar problemas para os seus usuários (por quê); se acha que a Internet pode resolver problemas dos seus usuários (por quê).

- Uso pesado, problemas, vida virtual, vício: o que entende por "usuário pesado"; verificar se o sujeito se considera um "usuário pesado"; o que acha que é o uso normal da Internet (por quê); o que entende por "mundo real" e "mundo virtual" (quais as vantagens e desvantagens de um e de outro); o quanto acha que é possível viver no "mundo virtual" (por quê); se acha que a vida virtual pode atrapalhar a vida real (por quê); se acha que existe o chamado vício na Internet (e, em caso positivo, que vício é esse, o que acha que vicia, se conhece alguém que se diz viciado, se já leu alguma coisa sobre isso, onde e quando ouviu falar de vício pela primeira vez) ; o que pensa da comparação dos efeitos da Internet com os efeitos causados por drogas (explorar diferentes tipos de efeito e a comparação com diferentes tipos de droga).

- Mudanças, transformações, objetivos: que papel tem a Internet na vida do entrevistado(a) hoje; se a vida dele(a) mudou depois da Internet; se o entrevistado(a) acha que ele/ ela próprio(a) mudou depois da experiência com a Internet; o que o/a entrevistado(a) procura na Internet.

No início da entrevista também eram coletados dados objetivos do sujeito: tempo de acesso à Rede, idade, sexo, escolaridade e ocupação/profissão. Como forma de registro, fez-se uso de gravações.

\section{Análise dos dados}

Todas as entrevistas foram integralmente transcritas e submetidas às técnicas de análise de discurso propostas por Nicolaci-da-Costa $(1989,1994)$. De forma muito resumida, a análise - qualitativa - é realizada em duas grandes etapas. Na primeira - a da análise inter-sujeitos são reunidas todas as respostas de todos os sujeitos a cada uma das perguntas, o que nos propicia uma visão panorâmica dos depoimentos gerados por cada uma de nossas questões. As respostas recorrentes nos discursos coletados e analisados nesta etapa já nos apontam os primeiros resultados - ou seja, as tendências centrais das respostas dadas pelo grupo como um todo -, embora estes ainda sejam inconclusivos. Já na segunda etapa - a da análise intra-sujeitos -, tomam-se as respostas de cada um dos sujeitos como um único conjunto dentro do qual são analisados possíveis conflitos de opiniões, inconsistências entre respostas, sentimentos contraditórios, etc. Com o insight ganho nesta segunda etapa, retornase à primeira e reanalisam-se novamente os conjuntos de respostas dadas por todos os sujeitos a cada uma das perguntas. Este vai-e-vem (que pode ser repetido quantas vezes necessário) permite que dominemos o material a fundo e possamos detectar, além de vários não-ditos (pois o que não é verbalizado em uma resposta pode ser claramente sugerido em outra), os preciosos pormenores de sentimentos, dúvidas, mal-estares, conflitos internos e porquês que sempre buscamos.

\section{Resultados relevantes}

Esta pesquisa mostrou-se muito produtiva. $\mathrm{O}$ roteiro acima descrito gerou uma grande quantidade de dados, que vêm sendo analisados por tópicos. Gerou, por exemplo, importantes informações sobre novas formas de defesa e de administração da privacidade. Estas, que receberam o nome de "tecnologia da intimidade", foram tornadas públicas em Nicolaci-da-Costa (2000). A mesma pesquisa revelou, também, a existência de um interessante e inesperado conflito entre o prazer que os usuários espontaneamente admitem derivar do tempo que passam online e a sua própria avaliação deste tempo como improdutivo. A análise desse conflito pode ser encontrada em Nicolaci-da-Costa (2002). No que se segue, serão apresentados somente os resultados relevantes para a discussão dos impactos subjetivos do discurso da patologia, tal como divulgado pela mídia.

Esses resultados podem ser agrupados em dois conjuntos principais. $\mathrm{O}$ primeiro diz respeito àquilo que os sujeitos explicitamente revelam sobre o uso que fazem da Rede. Já o segundo envolve uma análise dos recursos de que lançam mão para se proteger do discurso negativo 
da mídia, quer se distanciando deste, quer tentando, de alguma forma, integrá-lo ao seu cotidiano online. Esses dois conjuntos serão discutidos separadamente.

\section{A positividade do cotidiano online}

Não é preciso dizer que nossos entrevistados vêem sua experiência na Internet como positiva e dela derivam prazer. Que outros motivos poderiam levar todos a acessarem a Rede diariamente, por opção, durante, no mínimo, duas horas de seu tempo de lazer, ao longo de anos (na maior parte dos casos, mais de dois)?

$\mathrm{Na}$ realidade, os homens e mulheres que entrevistamos gostam tanto de suas atividades online (no mais das vezes, os bate-papos no IRC ou ICQ) que admitem haver cometido excessos nos primeiros tempos de conexão. Muitos fazem referência espontânea (não havia nenhuma pergunta a esse respeito) a uma fase de fascínio inicial, durante a qual confessam haver se excedido.

Paulo $^{2}$ (24 anos, médico), por exemplo, diz:

Já passei 20 horas [conectado] quando era iniciante. [Fazendo o quê?] Tentando desvendar os mistérios e maravilhas da Internet. Se meu corpo agüentasse, teria passado bem mais tempo, naquela ocasião.

E Roberta (39 anos, consultora de informática) acrescenta:

[Eu] não conseguia ficar durante o dia sem entrar numa sala de bate-papo. Hoje não sou mais assim...Agora tem o plateau. Tem uma hora em que você estabiliza (...) Tem uma hora que consegue conciliar um pouco mais as coisas. Tem a euforia, essa é a pior fase...

Essa fase de euforia, no entanto, parece já ter sido ultrapassada. Todos os entrevistados revelam acessar a Rede durante um número de horas regular, na maior parte das vezes, cerca de 2 horas diárias. (Há, no entanto, alguns poucos - que o fazem por até 6 horas diárias.)

Passada a fase de descoberta, a Internet se inseriu em suas vidas de uma forma prazerosa, porém estável. Do psicanalista de 56 anos de idade ao hacker de 20, passando pela professora de inglês de 23 , nossos 20 entrevistados revelam que a Internet hoje faz parte de suas atividades rotineiras de lazer e pesquisa. Vários admitem, inclusive, ter substituído algumas dessas atividades pelo uso da Rede. Desde que começaram a acessá-la, estes passaram a ver menos televisão, falar menos ao telefone, visitar menos bibliotecas, ler menos jornais impressos e, pelo menos em um caso, dormir menos.

Contrariamente à ausência de limites que muitos alegam caracterizar o uso da Rede, todos têm horários mais ou menos fixos de ligar o computador e de acessar a Rede, estabelecidos em função de seus compromissos e atividades diárias (tanto nos dias de semana quanto no fim-de-se- mana). Na maior parte dos casos, conectam-se principalmente à noite nos dias de semana (de dia estudam ou trabalham). Já nos fins-de-semana, conectam-se de dia (e geralmente por menos tempo) porque gostam de fazer programas noturnos. Muitos lidam com o computador com a mesma naturalidade com que lidam com a televisão ou o rádio. Deixam-no ligado todo o tempo que estão em casa, embora acessem a Rede somente em determinados horários. Seguem-se dois exemplos.

Ricardo (21 anos de idade, estudante de nível superior):

A primeira coisa que eu faço quando eu chego em casa é entrar no meu quarto e ligar o computador. E só desligo na hora de dormir. (...) Normalmente acesso [a Internet] de dia, de tarde, no fim da tarde. De noite eu não acesso... Minha namorada mora lá em casa. Quando ela chega em casa ela não gosta que eu fique no computador. (...) Eu não tenho muito o hábito de acessar no fim de semana...

Soraya (22 anos de idade, estudante de nível superior):

[Ligo o computador] assim que chego em casa. Já faz parte da rotina. Chego, ligo o rádio, vejo se tem algum recado na secretária e ligo o computador. (...) Durante a semana acesso [a Internet] à noite, quando chego do estágio. No final de semana, acesso de dia, porque à noite, sabe como é, tenho os meus programas. Sábado à noite...

O que fazem quando estão conectados? Também contrariamente ao que é divulgado a respeito do isolamento social, eles usam a Rede principalmente para bater papo, não com quaisquer desconhecidos, mas com pessoas com as quais podem criar vínculos on-line e com seus amigos da vida "real". Por isso mesmo, gostam de conhecer pessoas novas nos relativamente reservados canais de bate-papo do $\operatorname{IRC}^{3}$ e não nas bastante públicas salas de $\mathrm{Web}_{\text {chats }}{ }^{4}$.Mas isso não é tudo. O programa de bate-papo que mais apreciam é o ICQ ${ }^{5}$, que poderia ser descrito como uma espécie de ponto de encontro online de amigos da vida "real". Todos também fazem uso diário do e-mail.

Ainda contrariando a crença, divulgada pela mídia, de que a auto-exposição a desconhecidos os deixa completamente vulneráveis a diversos tipos de perigo, nossos entrevistados revelam não ser tão ingênuos nem tão indefesos como poderíamos ser levados a pensar. Sua experiência on line já os fez desenvolver o que chamei de tecnologia da intimidade (ver Nicolaci-da-Costa, 2000) para controlar o grau de exposição que fazem de si mesmos na Rede.

Para isso, têm, no mais das vezes, diferentes endereços e-mail para diferentes finalidades. Um - do tipo webmail é sempre impessoal, revelando apenas dados fictícios. É esse o endereço que dão para estranhos ou usam para se cadastrar nos mais variados sites. 
Wanda (23 anos, professora de inglês), por exemplo, diz ter duas contas ativas:

Uma do meu provedor que se tornou mais pessoal, só para amigos e interesses mais sérios. Outra pelo hotmail." [Por quê?] "... porque pude tornar o nick mais impessoal e assim me cadastrar em alguns sites.

Fernando (24 anos, jornalista), por sua vez, tem três contas de e-mail porque:

Um [e-mail] é só profissional, o outro é o e-mail do meu provedor que é totalmente pessoal, sabe? Só dou para quem é camarada e o terceiro é hotmail, então é festa, quem pedir eu tô dando.

O IRC e o ICQ são usados seguindo estratégia de autoproteção análoga. No IRC, os papos podem até ser muito íntimos mas são geralmente acobertados pelo anonimato (embora os nicks - apelidos que identificam os freqüentadoressejam geralmente estáveis). Já no ICQ as identidades "reais" são sempre reveladas porque, como já foi dito, seu uso é restrito à manutenção das amizades feitas na vida "real" ou daquelas que foram travadas on line mas já se tornaram "reais".

Ronaldo (23 anos, jornalista), por exemplo, revela usar o ICQ:

... porque ele é o único no mercado que faz isso, te permite encontrar pessoas que você conhece para bater papo. É como marcar um encontro com seus amigos."

E Carla (20 anos, estudante de terceiro grau) diz:

No ICQ você só conversa com quem você já conversou, você já conhece e no IRC você conversa com qualquer pessoa que você nunca viu.

A vivacidade, tranqüilidade, desenvoltura, espontaneidade e coerência de seus depoimentos indicam que nossos entrevistados estão sendo sinceros. Em contraste com o que acontece em relação aos outros tópicos da entrevista, discorrem a respeito de sua larga experiência de uso da Rede de uma forma na qual estão sempre presentes (e pessoalmente envolvidos) por meio do uso sistemático da primeira pessoa do singular. Em outras palavras, há harmonia entre sua experiência e seu discurso: uma experiência pessoal vivida como positiva é relatada através de um discurso autoreferido e também positivo.

\section{Reações à negatividade do discurso dos perigos e da patologia veiculado pela mídia}

\section{Reações ao discurso dos perigos em geral: distanciamento, neutralidade e contradições}

Um discurso auto-referido sobre uma atividade cotidiana, como o que acabamos de discutir, não causaria nenhuma surpresa caso não fosse radicalmente abandonado quando nossos sujeitos passam a se pronunciar sobre os perigos que supostamente rondam o ciberespaço. Neste último caso, que já faz parte do segundo conjunto de resultados mencionado anteriormente, tem-se a nítida impressão de que deixam de falar por si mesmos e tornam-se porta-vozes do discurso sobre os perigos da Rede alardeados pela mídia. Esta é uma das estratégias de auto-proteção de que fazem uso.

Quando, por exemplo, perguntamos se acham que a Internet pode gerar problemas para seus usuários, um padrão de respostas é recorrente: praticamente todos os entrevistados nos dão depoimentos que pouco ou nada têm a ver com a sua própria experiência na Rede. Quase todos mencionam os perigos constantemente apontados pela mídia - o isolamento social, a substituição da vida "real" pela virtual, os assassinatos e seqüestros a partir de contatos virtuais, além da compulsão e da dependência associadas ao tão-falado vício - como os principais problemas gerados pela Rede.

Com exceção do caso do vício, que será abordado em detalhe na próxima seção, essa menção é feita por meio de recursos lingüísticos - como o uso do "você" genérico, ou de "pessoas" não especificadas, do impessoal verbo haver, de expressões como "tem gente que..." etc. - que sugerem distanciamento e neutralidade.

É deste modo que Ricardo (21 anos, estudante de nível superior), por exemplo, se refere à substituição do "real" pelo virtual: "A Internet (...) possibilita muitas maneiras de você se esconder e não lidar com o aqui e agora. A Internet fornece maneiras de você não lidar com a realidade em momento algum".

É também assim que Paulo (24 anos, médico) menciona, com aparente neutralidade, patologias dele distantes:

Sim [a Internet pode gerar problemas para quem a usa]. Há casos confirmados de comportamentos patológicos na Internet. Talvez pessoas com alguma predisposição. Mas de toda forma, são pessoas que apresentam distúrbios pelo contato com a Internet. A Internet pode ser tão boa ou ruim quanto quase todas as coisas, dependendo da intensidade de contato e da maneira de conviver com ela.

Essas e muitas outras respostas análogas parecem recitar trechos do discurso negativo da mídia. Parecem, também, estar bastante distantes da experiência positiva desses usuários. (É digno de nota o fato de que estes sequer relatam casos de pessoas que lhes são próximas. Declinam apenas os exemplos fornecidos pela mídia.) Porque fazem parte de um discurso articulado por profissionais, essas respostas são, entretanto, internamente coerentes. Essa coerência desaparece quando os entrevistados tentam abandonar sua condição de porta-vozes e colocar suas próprias opiniões. 
Neste último caso, encontram-se as respostas infreqüentes - que tentam integrar a positividade da experiência dos sujeitos ao discurso negativo propalado pela mídia. Estas, de modo análogo às mencionadas acima, também tentam passar distanciamento e neutralidade. Diferentemente daquelas, no entanto, são geralmente crivadas de contradições internas que revelam como é difícil, para esses usuários, integrar a positividade de seu cotidiano na Rede a um discurso negativo que lhes é passado como fundamentado em dados científicos.

Um bom exemplo é o depoimento de Ronaldo (23 anos, jornalista). Ele parece ter se dado conta de que há alguma discrepância entre o que é divulgado a respeito do isolamento social gerado pelo uso da Rede e aquilo que a sua própria experiência lhe mostra. Numa resposta confusa, que incorpora somente parte do discurso "oficial" sobre o isolamento, diz não saber ao certo se a Rede integra ou isola. De qualquer modo, coloca-se longe do perigo, por meio do uso do "você" genérico anteriormente discutido:

Você não pode falar que as pessoas não estão se comunicando porque estão. É comunicação, mas isso não justifica você ficar preso em um quarto sozinho se comunicando pelo computador. Você se isola mas, ao mesmo tempo, está integrado, na verdade é um novo grupo que você não sai do quarto.

Há, portanto, algumas tentativas frustradas de integração da experiência positiva ao sombrio discurso de perigos como a substituição do real pelo virtual, do isolamento social, de comportamentos patológicos extremos, etc. Na maior parte das vezes, no entanto, os entrevistados não parecem estar preocupados com essa integração. Revelam estar a par da existência desses perigos (pois já leram ou ouviram falar a seu respeito), mas não demonstram sentir-se ameaçados por eles.

\section{Reações ao discurso sobre o vício: tentativas de integração do discurso negativo da mídia ao cotidiano positivo dos entrevistados}

O mesmo não ocorre no que diz respeito aos seus depoimentos sobre o vício. O discurso do vício já está difundido e enraizado demais para não ameaçar usuários "pesados" como os nossos sujeitos. Isso ficou claro nas entrevistas. Todos fizeram menção ao vício muito antes que lhes colocássemos qualquer pergunta explícita sobre o mesmo. (Havíamos intencionalmente colocado estas no final do roteiro.) Assim sendo, uma nova forma de auto-proteção é por eles adotada. Esta envolve a tentativa de integração do discurso negativo do vício à sua rotina positiva.

Embora somente um dos nossos entrevistados revele não acreditar na existência do vício na Internet, os depoimentos coletados indicam que praticamente todos conseguem relativizar o discurso do vício e muitos já conseguem integrá-lo à sua experiência positiva da Rede por meio de diferentes estratégias. Comecemos pelas estratégias de integração, nas quais, como pode ser observado, os entrevistados retomam um discurso auto-referido.

A primeira dessas estratégias - que chamei de distanciamento jocoso - consiste em lançar mão da ironia para, relativizando o discurso do vício (ao qual todos demonstram ter sido expostos de uma forma ou de outra), poder integrá-lo à sua experiência de usuários pesados. Seguem-se alguns exemplos.

Paulo (24 anos, médico) relativiza sua afirmação de que ele próprio é viciado dando algumas boas risadas:

Sim. Acredito [no vício]. Penso ser um viciado em Internet, mas leve. [Risos]. (...) A Internet é importante na minha vida, mas consigo viver sem ela. (...) Não chamo de vício pela Internet, mas sim de "vício pelas pessoas" da Internet.

Rafael (20 anos, estudante de nível superior) brinca ao falar sobre seu próprio vício: "Eu já fui mais viciado, agora tô mais tranqüilo. Jesus me salvou! [Gargalhadas]"

E Aline (24 anos, estudante de nível superior), que ouviu falar de vício pela primeira vez numa lista de psicologia da qual participa, aponta o uso jocoso do termo "viciado" no que diz respeito à Internet: "Até eu já me disse viciada, mas foi de brincadeira."

A segunda estratégia de integração do discurso negativo da mídia ao seu próprio cotidiano positivo alia o distanciamento jocoso à qualificação do uso intensivo da Internet como o de um vício "socialmente aceito", "não nocivo", "não maléfico", etc. Pode-se dizer que, através desse tipo de operação, os entrevistados, na realidade, sutilmente desqualificam o uso intensivo da Internet como vício.

Esta é a estratégia da qual se utiliza Wanda (23 anos, professora de inglês) que afirma em tom jocoso: "É um vício... não tão socialmente discriminado como o crack, mas bem aceito como a coca-cola."

Pedro (24 anos, advogado) também afirma acreditar que há dois tipos de vício: um vício não nocivo, como o de escutar música e outro de não conseguir se livrar da dependência. Só conhece o segundo por relatos da imprensa: Ah, eu acho que tem [vícios] de dois tipos. O vício como o
vício de escutar música, que não é uma parada nociva,
mas também acho que pode ter aquele vício da pessoa que
não consegue ficar sem mesmo, sabe? Agora, eu não co-
nheço ninguém que já tenha passado por esse problema,
de 'ai meu deus eu preciso e não tenho, arruma aí', mas eu
acredito, até por relatos de imprensa, acho que tem sim.
(...) De brincadeira todo mundo [diz ser viciado], mas
sério mesmo, "Sou viciado, não consigo viver sem", não. 
Miguel (19 anos, estudante de nível superior) parece concordar com Wanda e Pedro. Para ele, o vício na Internet não é maléfico. Aponta, também, o uso jocoso da palavra vício:

[A Internet] é uma coisa que preenche o tempo melhor do que a TV. Normalmente, se não estou fazendo nada, o reflexo direto é ligar a TV. A Internet, de repente, eu acho mais legal... Para mim é mais interessante, tem coisas mais interessantes.

Brincando a gente sempre diz (que é viciado). Sério, não. (...) Acho que não chega a ser um vício maléfico... Acho que é uma habitualidade. $O$ cara não vai morrer se ficar sem aquilo. Não vai passar mal se não puder acessar a Internet. (...) Quando apareceu a Internet eu ouvia o pessoal falando: "Estou com a Internet agora e não consigo largar, estou completamente viciado". Mas eu acho que é um uso jocoso da palavra.

É ainda interessante observar que, em suas tentativas de integrar discurso negativo e cotidiano positivo através do distanciamento jocoso e da desqualificação do uso intensivo como vício (ou de ambos), muitos entrevistados, tal como Miguel, oscilam entre a neutralidade sugerida por um discurso distanciado (como o que usam para falar do isolamento social, da substituição do real pelo virtual ou das patologias extremas) e a pessoalidade de um discurso auto-referido (como o que usam para falar de suas próprias experiências).

Isso não acontece quando os entrevistados lançam mão de uma terceira estratégia, agora de simples relativização do discurso do vício e não mais de integração deste à sua prática. Esta, não tão freqüente quanto as já descritas, consiste em atribuir ao "viciado" alguma dificuldade de ordem pessoal que o leva a adotar um comportamento compulsivo.

Cláudia (21 anos, estudante de nível superior) atribui o problema à solidão:

[Viciada] é a pessoa que vive para a Internet, não vê mais prazer em nada só em ficar conectado! Acho que uma pessoa solitária, que leva uma vida meio sem graça, entra na rede, tem experiências legais, acha que encontrou a solução para sua vida, não quer mais saber de nada!

Sérgio (56 anos, psicanalista) parece concordar com Claudia:

[Vício] seria a compulsão a entrar na Internet, não poder passar um dia sem entrar na Internet, ou então ter que ficar algumas horas, ou não sair para ficar na Internet. [O que gera isso é] uma vida vazia, uma vida pouco satisfatória.

Já Pedro (24 anos advogado) acha que pode haver um fator cultural que propicia a emergência do vício:

É o que falei dos EUA, não sei se é porque tem um maior número de usuários do mundo, ou e é porque eles são pancada mesmo. Mas isso é bem comum, acontece lá.
Tem gente fazendo tratamento, terapia, tem gente que perdeu o emprego porque não conseguia fazer mais nada, acontece.

Em todos os casos, no entanto, tem-se a nítida impressão de que, ao tomarem contato com o discurso sobre o vício, que a mídia enfatiza estar fundamentado em dados científicos, esses homens e mulheres, que usam a Internet intensivamente, foram forçados a fazer uma avaliação de seus hábitos. Deram crédito à sua própria experiência positiva, mas, tendo em vista a legitimidade científica atribuída pela mídia ao seu discurso, não puderam se descartar totalmente da crença no vício. Como conseqüência, acabaram desenvolvendo formas de relativizálo, ridicularizá-lo e, até mesmo, desqualificá-lo.

\section{Discussão: visões alarmistas geradas pelo medo do novo}

Os dias de hoje estão confusos. Parece haver diferentes pesos e medidas para avaliar o que fazemos na vida "real" e na vida "virtual".

Se alocarmos várias horas diárias à leitura, contaremos com aprovação praticamente irrestrita. Seremos, inclusive, vistos como cultos ou eruditos. Se passarmos essas mesmas horas diárias à frente da televisão, a aceitação será de outro tipo, porém automática. Faremos parte da legião mundial de telespectadores e certamente teremos muito assunto para conversa fácil. Se resolvermos manter contato diário com nossos familiares e amigos íntimos através de horas ao telefone, isso também será encarado como natural. Não seremos criticados por estarmos substituindo a "realidade" de um encontro face-a-face pela virtualidade de um contato telefônico.

Se, no entanto, deixarmos de lado todas essas atividades em sua versão "real" e dedicarmos o mesmo tempo a atividades semelhantes em sua versão "online", nosso comportamento poderá facilmente ser interpretado como uma de várias manifestações patológicas: isolamento social, fuga da realidade, medo de contatos reais, incapacidade de manutenção de conversas face-a-face, preferência por contatos anônimos, etc. Se passarmos duas ou mais horas diárias conectados (não importa que dediquemos mais tempo, por exemplo, à televisão ou aos livros) poderemos, inclusive, ser chamados de "viciados". O que está acontecendo?

Inovações tecnológicas que acarretam impactos profundos nos nossos modos de viver e de ser, embora frutos da curiosidade e da criatividade humanas, geram muito medo. Como mostra Zaremba (2001), esse medo é recorrente. Quando da invenção da escrita, temia-se que a memória fosse destruída. Quando da invenção da imprensa, temia-se que o imaginário religioso fosse assassinado pelos livros. Quando da invenção das primeiras máqui- 
nas, temia-se que os homens fossem transformados em suas engrenagens.

Nada disso aconteceu, como sabemos. Mesmo assim, esse antigo medo (que assume as mais variadas formas) ressurge com a entrada em cena da Internet. É partilhado pela grande maioria daqueles que já viveram o suficiente para conhecer um estilo de vida estável. Estes que podem ser cientistas, pesquisadores, jornalistas, profissionais liberais, donas-de-casa, aposentados e até mesmo jovens estudantes - têm dificuldades de lidar com as instabilidades e transformações radicais que fazem parte de qualquer quadro de mudança social. Querem o conforto e a segurança do já conhecido e, por isso mesmo, vêem como negativa qualquer mudança.

Dessa maioria parecem fazer parte os proponentes dos discursos que vimos discutindo ao longo deste artigo. A partir de um apego extremado a uma ordem que está sendo profundamente alterada pela difusão da Rede, interpretam comportamentos e sentimentos desconhecidos, gerados por uma nova realidade, como desvios das normas de conduta estabelecidas na ordem pré-digital das sociedades contemporâneas e atribuem-lhes o status de patológicos. Dou um exemplo. De acordo com as normas prédigitais, integração social significa estar em contato "real", ou físico (mesmo que isso se dê por telefone!), com diferentes pessoas ou grupos. Assim sendo, não se qualifica como integração social o contato com os outros via Internet, mesmo que este crie fortes vínculos afetivos (a esse respeito, ver Costa, 2001). A partir dessa ótica, portanto, interagir por meio da Internet significa se isolar. Não é sequer aventada a possibilidade de estar emergindo uma nova modalidade de integração social.

A serviço dessa maioria - fazendo ou não parte dela encontram-se os jornalistas, cujas matérias divulgam o medo e contribuem para a consolidação de uma forma negativa de olhar para as transformações que ocorrem cotidianamente no mundo.

Tudo isso pode ter sérias conseqüências para os usuários. Primeiramente porque é muito difícil integrar uma experiência positiva a um discurso negativo que pretende interpretá-la. Essa dificuldade, por sua vez, alimenta outra, que vem sendo apontada como possível fonte de problemas psicológicos (ver Turkle, 1995; Nicolaci-da-Costa, 1998; Romão-Dias, 2001): a dificuldade de integrar à vida "real" aquilo que é vivido no mundo "virtual".

Em segundo lugar, no caso dos usuários brasileiros que entrevistamos, nossos resultados indicam que o discurso da patologia, com o qual são bombardeados quase diariamente pela mídia on e off line, acaba se transformando em uma espécie de teste do quanto são capazes de dar crédito à própria experiência e à avaliação que dela fazem.
Suas convicções e julgamentos têm que ser fortes o suficiente para minimizar os efeitos de um discurso que, embora os atinja principalmente através da mídia, parecelhes incontestável porque "científico".

Toda a sua experiência positiva na Rede não parece lhes dar segurança para contestar explicitamente o discurso da patologia ao qual são expostos. Felizmente, porém, eles aprenderam a relativizá-lo e até mesmo a ridicularizá-lo através de diversas estratégias que, como vimos, vão do simples distanciamento ao uso do humor. É desse modo indireto que se contrapõem a um discurso cuja alegada legitimidade poderia ser massacrante. É deste mesmo modo que praticamente todos, com maior ou menor dificuldade, revelam o quanto dão crédito à sua própria experiência.

Tudo bem. Eles passaram no teste e mostraram que são saudáveis. Ficam, entretanto, algumas perguntas. Quantas horas de angústia não terão sido enfrentadas até que essas soluções de compromisso fossem encontradas? Será isso necessário ou está mais do que na hora de, na qualidade de pesquisadores, fornecermos aos cada vez mais numerosos usuários da Internet, um discurso que também contemple os aspectos positivos da vida online?

\section{Agradecimentos}

Esta pesquisa contou com o apoio do CNPq. Dela participaram, em diferentes momentos, os seguintes alunos do Departamento de Psicologia da PUC-Rio, muitos dos quais foram ou são bolsistas de iniciação científica: Priscila França Dib, Fernanda Vanni, Sabrina Presman, Carla Pannetti, Bianca Castro Dantas, Vanessa Cervinho Viana, Fernando Vilela, Cristiane Mastrangelo Ebecken e Érika Falcão Ramalho. Agradeço à Professora Eva Jonathan por todo o material bibliográfico fornecido e pela leitura crítica de uma versão anterior deste trabalho.

\section{Referências}

Clay, R. A. (2000). Linking up online. Monitor on Psychology, 31(4), 2023.

Costa, A. C. A. (2001). IRC: uma nova alternativa para as relações entre as pessoas. Dissertação de mestrado não-publicada, Pontifícia Universidade Católica do Rio de Janeiro, Rio de Janeiro.

deAngelis, T. (2000). Is Internet addiction real? Monitor on Psychology, 31(4), 24-27.

Instituições tentam curar viciados em Internet. (1996, 20 de novembro). Folha de São Paulo. Acesso em 12 de fevereiro de 2001, de http:// www.uol.com.br/bibliot/.

Internet vira vício para 10\% dos usuários. (1998, 30 de agosto). Folha de São Paulo. Acesso em 12 de fevereiro de 2001, de http:// www.uol.com.br/bibliot/.

Greenfield, D. (1999). Virtual addiction: Help for netheads, cyberfreaks, and those who love them. New York: New Harbinger. 
Greenfield, D. (2000). The net effect: Internet addiction and compulsive Internet use. Acesso em 19 de fevereiro de 2001, de http://www.virtualaddiction.com/neteffect.htm.

Grohol, J. M. (1999). Internet addiction guide. Acesso em 29 de agosto de 2001, de http://psychcentral.com/netaddiction.

Médico diz que Internet vicia como cocaína. (1997, 7 de agosto). Jornal do Brasil, p. 1.

Kraut, R., Lundmark, V., Patterson, M., Kiesler, S., Mukopadhyay, T., \& Scherlis, W. (1998, setembro). Internet paradox. A social technology that reduces social involvement and psychological well-being? American Psychologist. Disponível em http://www.apa.org/journals/ amp/amp5391017.html.

Labov, W. (1973). The logic of nonstandard English. In N. Keddie (Org.), Tinker, tailor... The myth of cultural deprivation (pp. 21-66). Harmondsworth: Penguin.

Leitão, C., \& Nicolaci-da-Costa, A. M. (2000). Psicologia clínica e informática: por que essa inusitada aproximação? Psicologia Clínica, 12(2), 189-205.

Morais, J. (2000). Armadilha digital. Superinteressante, 14(10), 64-70.

Nicolaci-da-Costa, A. M. (1989). Questões metodológicas sobre a análise de discurso. Psicologia: Reflexão e Crítica, 4(1/2), 103-108.

Nicolaci-da-Costa, A. M. (1994). A análise de discurso em questão. Psicologia: Teoria e Pesquisa, 10(2), 317-331.

Nicolaci-da-Costa, A. M. (1998). Na malha da rede: os impactos íntimos da Internet. Rio de Janeiro: Campus.

Nicolaci-da-Costa, A. M. (1999). Caught in a World Wide Web: the Internet and the New Man. In E. R. Larreta (Org.), Media and social perception (pp.155-177). Rio de Janeiro: UNESCO, ISSC, EDUCAM.
Nicolaci-da-Costa, A. M. (2000). A tecnologia da intimidade. In Sociedade Brasileira de Computação (Org.), Anais do III Workshop de Fatores Humanos em Sistemas Computacionais (pp. 1-11). Porto Alegre: Autor.

Nicolaci-da-Costa, A. M. (2002). Quem disse que é proibido ter prazer online? Identificando o positivo no quadro de mudanças atual. Psicologia: Ciência e Profissão, 22(2), 12-21.

Viciados em Internet. (1997, 8 de dezembro). O Globo, p. 20.

Romão-Dias, D. (2001). Nossa plural realidade: um estudo sobre a subjetividade na era da Internet. Dissertação de mestrado não-publicada, Pontifícia Universidade Católica do Rio de Janeiro, Rio de Janeiro.

Stanford Institute for the Quantitative Study of Society - SIQSS (2000). Press Release. Disponível em: http://www.stanford.edu/group/siqss/ Press_Release/press_release.html.

Turkle, S. (1995). Life on screen: identity in the age of the Internet. New York: Touchstone.

Trapped in the Internet? (1998). Washington Post. Acesso em 7 de setembro de 1998, de http://www.washingtonpost.com.

Weare, C. (2000). Internet statistics unsound: media reponting on Internet studies misses fundamental problems. Online Journalism Review. Acesso em 20 de maio de 2000, de http://ojr.usc.edu/content/ print.cfm?print $=370$.

Young, K. (1996). Internet addiction: the emergence of a new disorder. Acesso em 20 de fevereiro de 2001, de http://www.netaddiction.com.

Young, K. (1998). Caught in the net. New York: John Wiley \& Sons.

Zaremba, R. (2001). Escrevendo (ou seria 'teclando'?!) o homem do século XXI. Dissertação de mestrado não-publicada, Pontifícia Universidade Católica do Rio de Janeiro, Rio de Janeiro.

\section{Notas}

1 Ver, por exemplo, o site de Young (http://netaddiction.com) e o de Greenfiel (http://www.virtualaddiction.com). Em ambos são divulgados resultados de pesquisas e oferecido tratamento online.

2 Para preservar a identidade dos nossos sujeitos, todos os nomes usados são fictícios.

3 Que se caracterizam pela freqüência assídua de grupos mais ou menos fechados cujos membros aceitam ou não os recém-chegados. Porque são mais dificeis de acessar (requerem software específico), fechados e seletivos, os canais de IRC (Internet Relay Chat) tendem a gerar vínculos entre os seus freqüentadores (a esse respeito, ver Costa, 2001).

4 Como, por exemplo, as salas de bate-papo dos grandes portais. Segundo nossos entrevistados, estas, porque fáceis de acessar a partir de qualquer browser (programa de navegação online como o Netscape ou o Internet Explorer), são freqüentadas por qualquer um e, por, isso mesmo, são descompromissadas demais e não propiciam a construção de vínculos permanentes.

5 Diferentemente do IRC e dos Web chats, o ICQ (acrônimo de I seek you, ou, Eu procuro você) é um programa de comunicação online freqüentado majoritariamente por pessoas que se conhecem na vida "real".

Ana Maria Nicolaci-da-Costa, doutora em Psicologia pela London University (Reino Unido), é professora do Departamento de Psicologia da Pontifícia Universidade Católica do Rio de Janeiro. Endereço para correspondência:

Rua Marquês de São Vicente, 225, Gávea, 22543-900, Rio de Janeiro, RJ.

Telefone.(021)3114.1183/3114.1185. Fax (021)3114.1187. E-mail: anicol@psi.puc-rio.br. 